\title{
Gender and Social Legitimacy of Entrepreneurship: Contribution to Entrepreneurial Intention in University Students from Chile and Colombia
}

\author{
Karla Soria ${ }^{1 *}$, Guillermo Honores ${ }^{1}$, Julián Gutiérrez ${ }^{2}$
}

\begin{abstract}
The research extends the application of TBP model including gender and SLE as moderator and mediator, respectively, and see if the prior results in developing countries are coincident with those of this research. In sum, the results could strength the contribution of TBP model including SLE as mediator and gender as moderator through EI. The research is a bi-country study based on 351 University students of business management in Chile and Colombia (245 students corresponds to Chile and 106 corresponds to Colombia). The data were subjected first to a confirmatory factor analysis (CFA) using Lisrel package. A structural equation model (SEM) analysis by the method of partial least squares (PLS) was used to test hypotheses. The results show that the Ajzen's model explains the EI in Chile; while in the case of Colombia, only two of the variables suite the model. The social legitimacy of entrepreneurship is a factor that mediates attitude toward entrepreneurship and entrepreneurial intention for both countries. Finally, gender moderates perceived control behavior for the less male culture, Chile, according to Hofstede dimension.
\end{abstract}

Keywords: entrepreneurial intention; Ajzen Model; gender; social legitimacy of entrepreneurship; Chile; Colombia

Submitted: August 15th 2016/ Approved: September 12th 2016

\section{Introduction}

The entrepreneurial intention is a good predictor of the action to be performed. In this case, the effort refers to create a new venture. Several models try to explain EI (EI) such as Shapero y Sokol (1982) and Krueger y Brazeal (1994). However, they are not the ones that have the major influence in the empirical analysis of EI. The model that best explains EI is the Theory of Planned Behavior (TPB) of Ajzen (1991). In this sense, this study adopts Ajzen's model to analyze the relationship between their factors and two more variables: gender and social legitimization of entrepreneurship to determine the influence on intention.

Around the world, some studies have compared EI in different countries and regions. Efforts can be documented, for example, Garcia et al., (2013); Liñán et al., (2011) and Sánchez (2009). Liñán et al. (2011) compare EI for students in two Spanish cities by verifying that there are different effects in both places. Sánchez (2009) performed a comparison between EI in two countries of the European Mediterranean and one in Latin America, identifying variation between self-efficacy and $\mathrm{EI}$ in both regions. However, the literature on regional comparative analysis regarding EI and related variables is scarce and there is even less in emerging economies such as Colombia and Chile.

Hofstede (1980), distinguishes four dimensions that characterize the cultures: power distance (PDI), uncertainty avoidance (UAI), individualism-collectivism (IDV) in a country and masculinity-feminity (MAS). Later, Hofstede (1995) includes a new dimension, the fifth orientation toward the short/long term of individuals (LTO). McGrath et al. (1992) design a profile of a potential entrepreneur as a person with high PDI, low UAI, high IDV and high MAS. Indeed, entrepreneurial activity has been positively linked to high PDI (Busenitz and Lau, 1996), ranking low on UAI (Shane, 2000), individualistic cultures (Gupta et al. 2008; Hofstede, 2004) and high MAS.
Chile and Colombia differ mostly on the MAS and IDV dimension, so the analysis of the EI impact considers these dimensions. According to those two dimensions, Chile has pair individualism and a less masculinity culture than Colombia's. Taking into account these cultural characteristics, the research will contribute determining if the cultural differences generate the different impact of SLE to EI through subjective norms and attitude toward entrepreneurship. It is interesting to know how SLE can mediate the further action of creating a new business (Kibler et al. 2014) through EI.

This study makes its contribution in two points of interest. First, the research goes deeper on the study of the Ajzen's Theory of Planned Behavior (TPB). Specifically, the study includes two additional variables (social legitimacy of entrepreneurship and gender) that could reinforce the relationship of subjective norms (SN), personal attitude toward entrepreneurship (ATE) and perceived behavioral control (PBC) over EI. The first variable introduced in the analysis is the social legitimacy of entrepreneurship (SLE). The SLE could influence the positive or negative perception to become an entrepreneur. These beliefs probably affect ATE directly or indirectly, within will affect EI, either in a direct or indirect way. Specifically, the research compares the impact of SLE over EI in two Latin American countries (Chile and Colombia). Cultural differences in either country could show different effects.

The second variable included on the TPB, goes deeply and to identify the moderate gender effect over EI in Chile and Colombia. In agreement to Hofstede's dimensions, Colombia is a society with great differences in the allocation of roles. The MAS level for Colombia is similar to Germany and USA. So, Colombian culture should be more oriented to the competitiveness, independence and aggressiveness and autonomy (male stereotype). Furthermore, women who

(1) School of Business Science, Universidad Católica del Norte, Coquimbo, Chile

(2) Faculty of Administration, Universidad Piloto de Colombia

*Corresponding author: ksoria@ucn.cl 
are trying to create a new venture in less developed countries have to face challenges, like lack of training, networks access and low levels of social support and high fear of failure (Amorós et al. 2014). So including the gender variable as a moderator in the TPB model, it could be found new insights to understand deeply the way TBP explains EI in Latin American and emerging countries.

In addition to checking the bond of SLE and gender on EI in the TPB model, the study contrasts these constructs between two developing economies. With respect on SLE, few studies connect the social legitimacy of entrepreneurship with EI, but there are no comparisons of Latin American countries linking SLE with EI. This point is of interest, given that while both Chile and Colombia during recent years have been in the process of constant economic growth, there is no data to infer differences or similarities to EI and possible factors associated with SLE that affect one or another. There is an opportunity to present new evidence about the relationship between culture gender, and EI for developing countries of South America. Also, it is relevant to take account that most of EI literature has done in Northern Hemisphere countries, and some scholars suggest then it is not convenient to extrapolate results of development countries through economies in development (De Vita et al., 2014). Consequently, it is a contribution extending the application of TBP model including gender and SLE as moderator and mediator, respectively, and see if the prior results in developing countries are coincident with those of this research. In sum, the results could strength the contribution of TBP model including SLE as mediator and gender as a moderator through EI.

It is necessary to clarify that although Chile and Colombia are two emerging economies, there are another differences that are worth mentioning. Chile has 17.7 million inhabitants, Colombia $47.7 \mathrm{mi}-$ llion by 2014. Chile has a GDP per capita of the order of USD 16700 while in Colombia was USD 6571. For the same period detailed previously, 2008 - 2013, unemployment in Chile stood at 7.6\%, while in Colombia was $11.2 \%$ on average. These data allow us to find differences on the macroeconomic situation in these two countries. Thereby its results motivated to analyze the entrepreneurial reality of these Latin American countries but with macroeconomic indicators with some differences.

The organization of the paper is as follows. The next section presents the theoretical framework about EI, gender and social legitimacy of entrepreneurship, as well as the detail of the hypothesis. The third section describes data, variables, and methodology used during the investigation. The following part analyzes the results and discussion. The last section includes the conclusion and future lines of research.

\section{Theoretical Framework and Hypothesis}

\section{Models of Entrepreneurial Intentions}

The EI is the key concept to understand the process of creating a new business, i.e. one that mobilizes people to become entrepreneurs, those who choose a career of setting up their own company. About this, there is a great group of studies relating to personal characteristics (orientation to achievement, self-efficacy, propensity / tolerance to risk, leadership, and ability to generate networks). There is also another approach to research linking individual character variables with those of the environment (Liñán et al. 2011). Additionally, EI seems connected with employment creation/decision, economic environment, availability of resources. In consequence, EI is related to behavior, attitudes, subjective norms and perceived behavioral control (PBC).

There are essentially three models that have tried to explain the EI of people. First, the model of business conduct, Shapero and Sokol (1982) with their perceived desirability and feasibility variables are reinforced with the propensity to act. Then the Theory of Planned Behavior of Ajzen (1991) has three explanatory variables: attitude towards entrepreneurial behavior (ATE), subjective norms (SN) and perceived behavioral control (PBC). Finally, Krueger and Brazeal (1994) combine both approaches, creating the model of the entrepreneurial potential. In all three models, there are individual as well as environment variables. Shapero and Sokol (1982) and Krueger and Brazeal (1994), consider the variable of perceived feasibility which includes the individual's own capabilities. This variable studies the internal characteristics that the person perceives to possess internally and thereby reinforces his interest in carrying out an unknown behavior, such as the start of a new business. In essence, the point is self-efficacy (Krueger and Brazeal 1994) and locus of internal control (Shapero and Sokol 1982; Ajzen 1991).

Theory of the Planned Behavior (Ajzen 1991) is the model that has been widely used because of their empirical results (Krueger et al., 2000; Liñán et al., 2011; Veciana et al., 2005). The TPB framework is the result of the three factors mentioned above: personal attraction to entrepreneurial activity and a positive/favorable or negative/unfavorable vision of the behavior (ATE), perceived social pressure of their nearest persons to develop the action or not $(\mathrm{SN})$ and the feel that the individual has the capabilities to carry out the conduct (PBC). In this case, the behavior is to decide to create a new firm (Robledo et al. 2015).

In the literature or TPB the dimension of attitude, which is usually permanent and stable, is a psychological construct that influences and predicts many behaviors (Krauss et. al. 2005). In general, the more favorable the attitude towards entrepreneurship is the EI's perform should increases. Additionally, PBC relates the election of an action than the individual thinks will be able to control and master. Perceived behavioral control is similar to self-efficacy of Bandura and is also included in the model of Krueger and Brazeal (1994). Finally, in the TPB model the dimension of subjective norms. Notice that if an individual perceives that his/her significant people (family or friends) endorse (or disapprove) the decision of become an entrepreneur, he/ she in more (or less) likely to try to perform it.

One concept, which is common to the three models mentioned before, is related to the culture or the environment of potential entrepreneurs. According to North and his Theory of Institutions (2005), the culture of the society reflects the collective learning, and these 
can affect the perceived desirability, which in turn can determine how the entrepreneurial environment is perceived. A favorable environment facilitates the desire to begin a business. The rules may reflect the influence of social values and attitudes. Also, it can be considered as the principal barrier to creativity and innovation (Shane, 2000). In the models described above, subjective norms are part of the variables that explain the EI of the model Ajzen (1991) and perceived desirability in the case of Shapero and Sokol (1982) and Krueger and Brazeal (1994).

This research uses the Ajzen's TPB to analyze the entrepreneurship process. In this sense, TBP used to explain the formation of EI three elements described above, the personal's attitude toward the action, subjective norms as the perception of closest person's opinions about entrepreneurship and the subject's perception of behavior control, defined as the perception of the difficulty or ease to become an entrepreneur. The application of the TPB in the entrepreneurship literature indicates that ATE, SN, and PBC typically explain 30\%-45\% of the variance in intentions Kautonen et al., (2013). Besides, Moriano et al. (2012) suggest that the strength of their influence on intentions varies between studies.

The TPB model has been verified in various countries over the past two decades, without inquiring into Latin American economies such as Chile and Colombia. Firstly, it is proposed to explain the EI, the relevance that may it has in young university students from the cities of Coquimbo (Chile) and Bogotá (Colombia). The first hypothesis would be to verify the fit of TBP model for each country considered in this research.

H1a: Personal attitude toward entrepreneurship, subjective norms, and perception of behavior control positive influences EI in Chile

H1b: Personal attitude toward entrepreneurship, subjective norms, and perception of behavior control positive influences EI in Colombia

\section{Social legitimacy of entrepreneurship (SLE)}

We assumed that the social legitimacy of entrepreneurship is part of the culture; that is to say that SLE can influence the intention and subsequent action to be taken. This factor is recognized as such in the Theory of Institutions, Kibler et al. 2014. As they mention, beliefs and behavior of people are structured according to the rules and regulations prevailing in the institutional environment. These aspects may encourage or put up barriers to individual decisions, such as creating a business.

There are several definitions for the SLE. Generally, they tend to agree that SLE is a "generalized perception or assumption that the actions of an entity are desirable, proper and suitable" (Suchmann 1995). This document follows the definition used by Kibler et al. (2014). That is, it includes three dimensions for the social legitimacy of entrepreneurship: pragmatic, moral and cognitive. It is notable that the pragmatic recognition refers to the interests of the individual; while the moral appreciation has to do with the analysis of rules. Finally, cognitive identification relates to the fact that there may be a negative/ positive valuation or none towards entrepreneurship.

García-Rodriguez et al. (2015) indicate that empirical studies have demonstrated how the cultural aspects of a particular region can affect intention, even more than economic variables. The four principal dimensions of Hofstede (1980), help to differentiate the culture among countries. As it was said before, Chile and Colombia have differences in two of the four dimensions of Hofstede (1980). Specifically, Chile seems to have a more individualism and less masculinity culture than Colombia. So, it is reasonable to expect differences in the effect to EI in both countries.

The entrepreneurship literature has studied the influence of cultural aspects on EI through cognitive mechanisms. Culture is made up of ideas, norms, and values. Also, Hofstede (1980) pointed out that culture is defined "as a collective programing of the mind that distinguishes the members of a group of people form others", Liñán et al. (2011). Besides, culture shaped individual's cognitive scheme.

Indeed with the research, culture could influence entrepreneurship through two ways. By one hand, through the social legitimization; and, by the other, promoting positive attitudes related creating a new firm (Davidsson 1995). Hofstede (1980) indicated that culture shapes people. Besides, the cognitive schemes derived from culture can help entrepreneurs in some aspects like reducing the uncertainty of making decision; facilitate the opportunity recognition and increasing the EI, focus of this study (Busenitz and Lau, 1996)

With the background described, the cultures differences in either country are expected to affect in different ways the variables of the TBP model. Especially, it is considered that SLE should be related the much greater extent to subjective norms and attitude toward entrepreneurship, because both are more linked with the environment. Taking account that Colombian culture is more cooperative than the Chilean's one, it is acceptable to expect that there could be differences in the effect of SLE over EI. This suggests the following hypothesis, considering that Chile is more individualistic than Colombia.

H2a: Social legitimacy of entrepreneurship mediates the impact of attitude towards entrepreneurship through EI with more strength in Chile.

H2b: Social legitimacy of entrepreneurship mediates the impact of subjective norms through EI with more strength in Chile

\section{Gender}

In the analysis of papers linked with EIs made by Liñán and Fayolle (2015), 30 documents were related to gender issues from the total of 409. The gender stereotypes in entrepreneurship is the focus of Gupta's contribution of Gupta et al. (2008 and 2009). Males are found to exhibit a more positive attitude towards entrepreneurship and a higher EI (Strobl et al., 2012), also a more positive feasibility. Several reasons can be argued to explain this fact. For example, women 
may perceive disadvantages in the self-employment option because of pregnancy and maternity leave in comparison with being an employee (Díaz-García and Jiménez-Moreno, 2010).

Additionally, women also perceived their environment to be more difficult, and they will be likely to have a lower sense of personal control over activities associated with entrepreneurial career than men (BarNir et al. 2011). Males and females have a difference impact in on EI; that is why a moderator for the three dimensions of the TPB model is gender.

There is a growing interest in research focused on women entrepreneurship (Gupta et al., 2008; Díaz-García and Jiménez-Moreno, 2010; Noguera, et al., 2013; y Ruizalba et al., 2015). So, the role of gender continues to be an area that could help to generate entrepreneurial education programs to reduce the gender effect in the creation of new firms. Some studies that have discussed this result indicates that males have a larger preference for entrepreneurial behavior than females (Ventura and Quero, 2013; Ruizalba, et al., 2015).

In regard to the link between $\mathrm{SN}$ and gender, some authors have emphasized the existence of business culture's predominantly masculine nature (Gupta et al., 2008; Ventura and Quero, 2013). In this sense, culture shows the women's entrepreneurship as less preferable and, the society gives less support for female, so women themselves perceive the option of creating a firm less desirable (Díaz-García and Jiménez-Montero, 2010).

Finally, women fill that they have less PBC required to develop a new business. In this sense, scholars have identified the fact that women choose not to become entrepreneurs because they perceived the lack of locus of internal control or self-efficacy (Maes et al. 2014). In the same way, female are less likely to be proud of their success and frequently attribute their exit to external sources or luck than to their own ability or effort (Verheul et al., 2012). So, gender might also have a moderating effect on the impact of EI. Negative feedback about their entrepreneurial abilities alters female student expectancies on their potential creation of a new firm more than in the case of their male partners.

The moderate effect of gender on TPB factors and the impact on EI is tested within the analysis. According to the Masculinity dimension of Hofstede (1980), Colombia has a culture more characterized by male stereotype. So with the arguments above described the research we aim to propose the following hypothesis.

H3a: Gender moderates the relationship between attitude towards entrepreneurship behavior and EI with more strength in Colombia.

H3b: Gender moderates the relationship between subjective norms and EI with more strength is Colombia.

H3c: Gender moderates impact of perceived behavioral control and EI with more strength in Colombia.
Figure 1 summarizes the hypothesis under study. It displays the interest of checking the mediate effect that could have the social legitimacy of entrepreneurship on the decision to start a new business and also if there exists the moderate effect of gender.

Figure 1: The study hypothesis

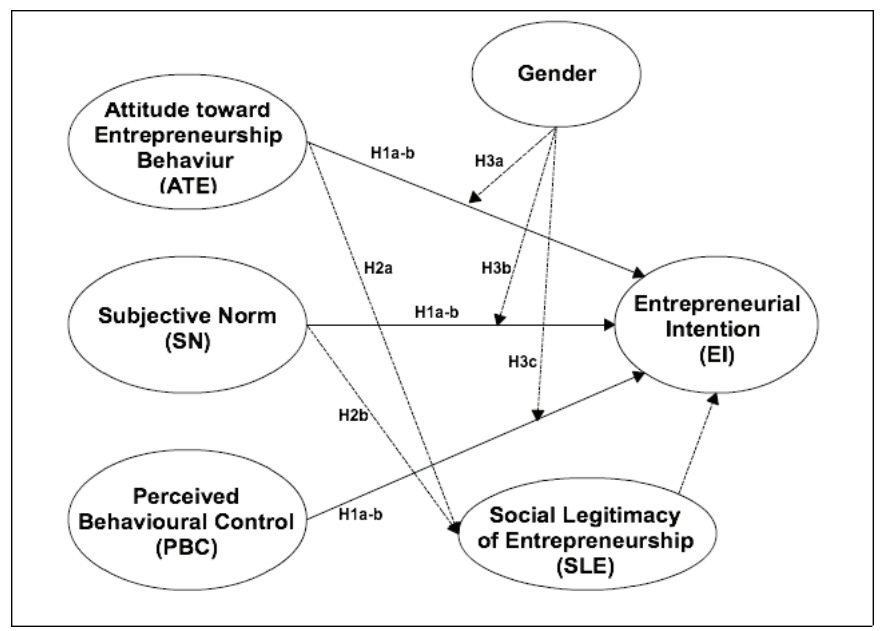

\section{Data and Variables}

Our empirical analysis is based on data obtained from a survey of university students in Chile and Colombia, between the months of January and July 2015. The study analyzes the responses of 351 University students in the area of business management from Chile and Colombia. The sample has 245 students from the Universidad Católica del Norte (Coquimbo, Chile) and 106 students from the Universidad Piloto de Colombia (Bogotá, Colombia). We did estimation using the structural equations model. The target population of this study was students of business administration. There are at least two reasons for selecting a sample of students to carry this research. Firstly, Sexton and Bowman (1986) observed that students of business administration are a convenient sample which provides good control in the comprehension and completion of these type of questionnaires. Also, they represent the best sample for interest of becoming an entrepreneur (Veciana et al., 2005)

The students answered the survey in a voluntary basis. They were provided with a link to access the survey. The principal results of the sample analyzed are shown in Table 1. Of the total sample, 150 students are men and 201 are women (43\% and 57\%, respectively). Respondent's age ranges from 18 to 39 years, with an average of 21 years and a standard deviation of 3 years. The 71 percent of Colombian and 56 percent of Chilean students indicate they have some previous work experience. Finally, 39 percent of Chilean students have a monthly family income lower than USD1000. So, the undergraduate in Colombia, in average, have a higher income. Only 12 percent of the sample have family incomes over USD1000. In Chile, 68 percent of the students' household income is lower than USD 2001, while the 40 percent of students in Colombia are in this range. 
Table 1: Characteristics of the sample

\begin{tabular}{|c|c|c|c|}
\hline & Total & Chile & Colombia \\
\hline Number of students & 351 & 245 & 106 \\
\hline \multicolumn{4}{|l|}{ Gender } \\
\hline Women & 201 & 144 & 57 \\
\hline Between USD 1001 and USD 2000 & $29 \%$ & $29 \%$ & $28 \%$ \\
\hline Between USD 2001 and USD 3000 & $17 \%$ & $13 \%$ & $25 \%$ \\
\hline Between USD 3001 and USD 4000 & $10 \%$ & $8 \%$ & $15 \%$ \\
\hline Between USD 4001 and USD 5000 & $5 \%$ & $5 \%$ & $8 \%$ \\
\hline \multicolumn{4}{|l|}{ Labour Experience } \\
\hline Yes & $60 \%$ & $56 \%$ & $71 \%$ \\
\hline No & $40 \%$ & $44 \%$ & $29 \%$ \\
\hline
\end{tabular}

The following is a description of the variables. Each question in the survey has a Likert scale from one to five, where 1 indicates strong disagreement and five total agreement.

1. Entrepreneurial Intention (EI): Dependent variable. It is constructed from a set of six phrases adapted from the instrument designed by Liñán and Chen (2009) and Thompson (2009).

2. Perceived Behavioral Control (PBC): A set of five sentences define this variable. They were taken from the instrument of Liñán and Chen, (2009).

3. Subjective Norm (SN): A basis of three questions represents this independent variable and it concerns the relevance that has the immediate environment of the student about entrepreneurship. The questions were taken from the instrument and Liñán and Chen (2009).

4. Attitude towards Entrepreneurship Behavior (ATE): This variable is measured through seven sentences, describing the attitude of the person in different circumstances. They are taken from the instrument created by Liñán and Chen (2009).

5. The social legitimacy of entrepreneurship (SLE): This variable is measured through seven phrases that describe the person's environment. It considers the valuation of the city of the student's current residence. Kibler et al., (2014) used this statements.

\section{Results}

A structural equation model (SEM) analysis by the method of partial least squares (PLS) was used to test hypotheses. The data obtained by the instrument described above were subjected first to a confirmatory factor analysis (CFA) using Lisrel package.

Table 2 shows the questions that explain each of the latent variables. Questions not charged well for each construct were eliminated, leaving only those that altogether point out and have the better goodness of fit indices. The results show acceptable composite reliability index (IFC) for each of the constructs, the same as the extracted variance (AVE). By measuring the validity of the scales used, it can be observed that the criterion of Hair et al. (1998) are acceptable and valid each of the scales, the lowest being that of subjective norms (SN).

When analyzing goodness of fit index, we show that the ratio Chisquare/degrees of freedom is acceptable, being well below the 1.8 maximum acceptable is 3. The same applies to the RMSEA 0.049 being well below the maximum acceptable 0.8 and NNFI, GFI and AGFI still all very close to 1 . 
Table 2: Confirmatory Factor Analysis

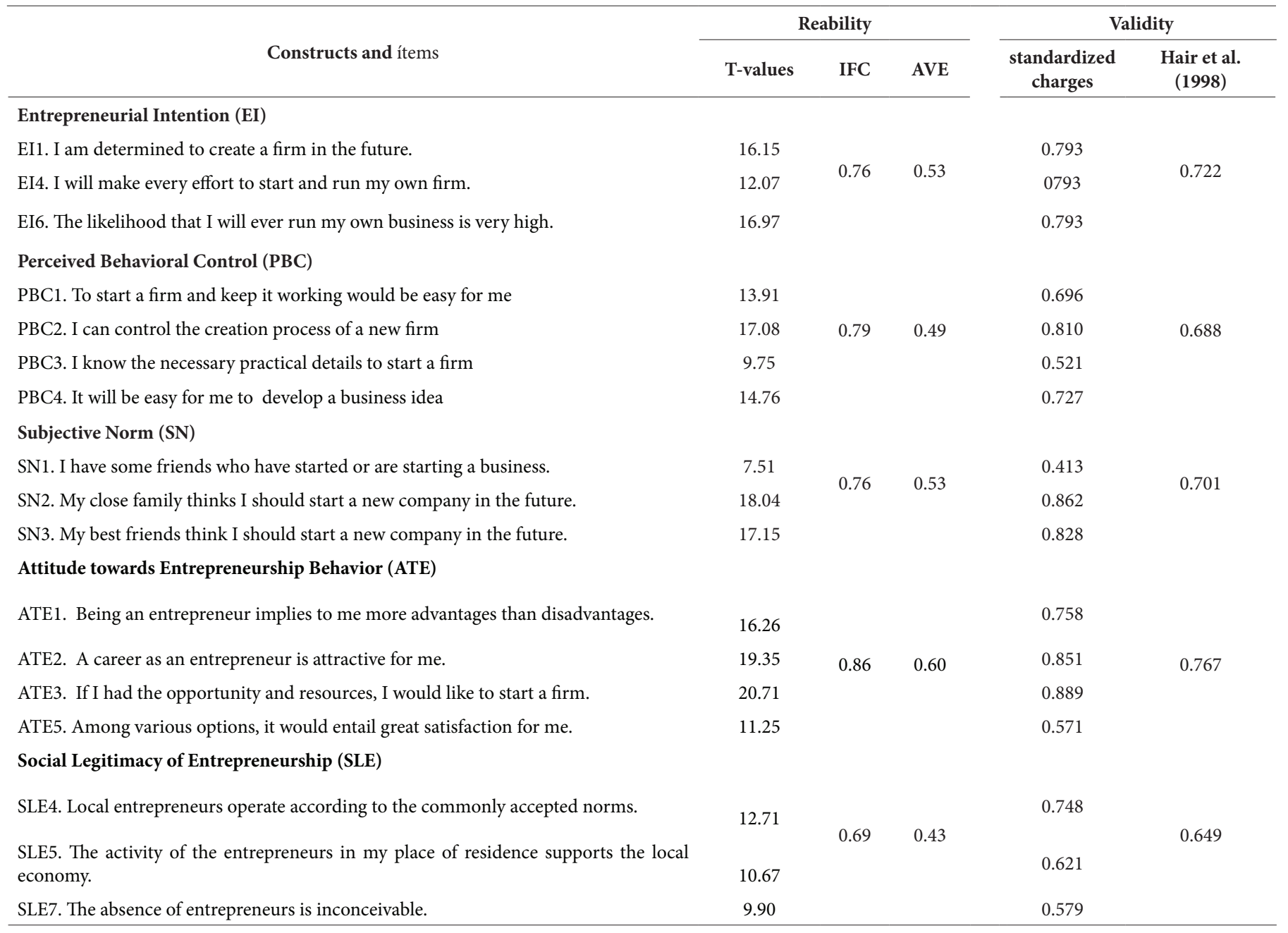

$\chi^{2}(109)=196.71, \mathrm{p}=0.00 ; \mathrm{RMSEA}=0.049 ; \mathrm{SRMR}=0.044 ; \mathrm{NNFI}=0.984 ; \mathrm{CFI}=0.987 ; \mathrm{GFI}=0.936 ; \mathrm{AGFI}=0.9105$

Table 3 shows the correlations of each construct with others. We show that the most intense relationships between different constructs are: EI with the ATE with close to $76 \%$ levels: followed, by PBC with ATE with a correlation value of $66 \%$. The lowest and negative correlation lies with the gender with SLE.

Table 3 Item - Construct Correlations

\begin{tabular}{ccccccc}
\hline & EI & ATE & SN & PBC & SLE & \\
\hline EI & 1 & & & & \\
ATE & 0.764 & 1 & & & \\
SN & 0.562 & 0.520 & 1 & 1 & 1 \\
PBC & 0.644 & 0.657 & 0.518 & 0.305 & & \\
SLE & 0.328 & 0.435 & 0.346 & 0.006 & -0.094 & 1 \\
GEN & 0.032 & 0.001 & 0.002 & & \\
\hline
\end{tabular}

After evaluating the reliability of the variables and identifying each of the constructs with their respective items, it proceeds to use SEM for EI models, both for Chile and Colombia. 
Table 4: Regression results in Ajzen's Model: Chile and Colombia

\begin{tabular}{lcc}
\hline & Chile & Colombia \\
Model 1 & \\
Main effect & & \\
Attitude Toward Entrepreneurship & & $0.5828^{* * *}$ \\
Subjective Norm & $0.5437^{* * *}$ & 0.07051 \\
Perceived Behavioral Control & $0.2138^{* * *}$ & $0.2267^{* * *}$ \\
Gender & $0.1744^{* * *}$ & -0.371 \\
Age & 0.0384 & -0.1319 \\
Study & -0.0124 & -0.07761 \\
Income & -0.0034 & 0.1028 \\
Adjusted R Square & 0.0044 & 0.6318 \\
F & & $24.02^{* * *}$ \\
\hline
\end{tabular}

${ }^{* * *} \mathrm{p}<0.01,{ }^{* *} \mathrm{p}<0.05$

In the above table, the model results Ajzen (1991) for both countries are observed. We point out that for the standard model, the results are better for Chile than Colombia, being non-significant subjective norms for the latter, so that they can give support to the hypothesis H1a and only partial H1b. Results show that ATE and PBC are the only significant variables for Colombia, but have a robust impact to EI than in Chile.

Table 5 shows the mediate effect of social legitimacy of entrepreneurship. We compared the results for model 1 (Ajzen: ATE, SN y PBC) with model 2, which include SLE as the dependent variable and Ajzen's variables (ATE, SN y PBC). Later the third model incorporates SLE as an independent variable for EI. All of these three regressions are considered to measure the SLE mediator effect in the Ajzen's model of EI. Test of Sobel is used to verify the mediate effect.

The results show that SLE only mediates the attitude toward entrepreneurship for either country. This mediate effect is a positive one. This relationship has partial support to $\mathrm{H} 2 \mathrm{a}$; that is to say, a significant mediate impact between ATE and EI, but Chile has a more strength in the effect through EI (0.5757 vs. 0.5402). We could not prove the second hypothesis related to SLE as a mediator. Besides, we prove that $\mathrm{PBC}$ is significant in model 1 and model 3. It is interesting to note that SN explains SLE in Colombia, so there is a direct effect between SN and SLE, but not through EI neither direct or indirect.

Table 5: Regression results SLE as Mediator: Chile and Colombia

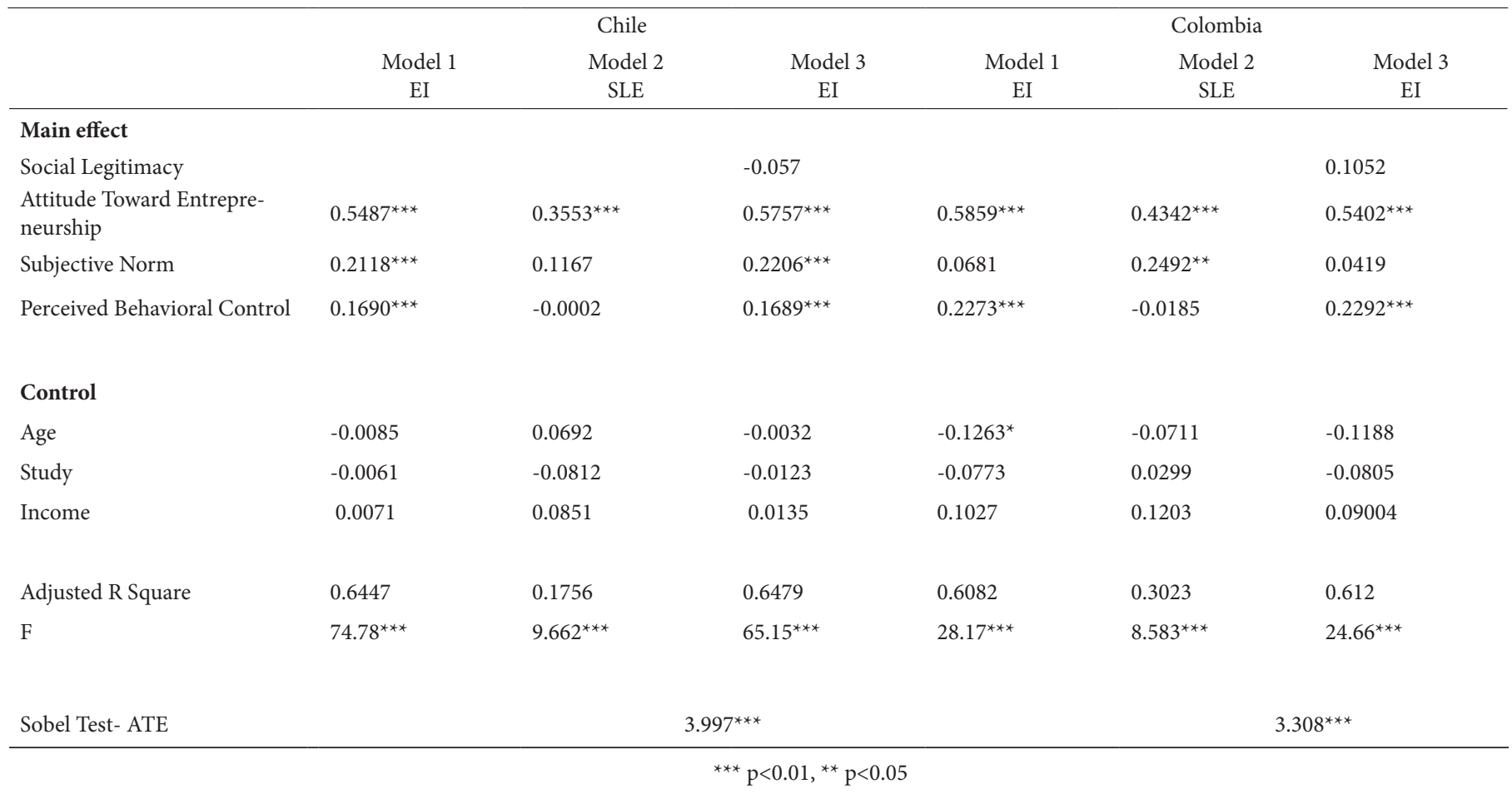


After evaluating the hypothesis testing Ajzen model and mediate impact of SLE, we will analyze if there exists a moderate effect of gender through EI. It proceeds to use SEM for two models of EI, both for Chile and Colombia. We run two. The first one includes only the standard variables in the models and Gender as another independent variable. In the second regression, we incorporate gender as a moderator. When we incorporate interactive effect of gender with ATE, $\mathrm{PBC}$, and $\mathrm{SN}$, the moderate relationship is significant only for Chile, and specifically for PBC. These results allow accepting $\mathrm{H} 3 \mathrm{c}$. So gender does not affect ATE for either country through EI.

Table 6: Regression results Gender as Moderator: Chile and Colombia

\begin{tabular}{|c|c|c|c|c|}
\hline & \multicolumn{2}{|c|}{ Chile } & \multicolumn{2}{|c|}{ Colombia } \\
\hline \multicolumn{5}{|l|}{ Main effect } \\
\hline Attitude Toward Entrepreneurship & $0.5437^{\star * *}$ & $0.54732^{* * *}$ & $0.5828^{* * *}$ & $0.5939^{* * *}$ \\
\hline Subjective Norm & $0.2138^{\star * *}$ & $0.21564^{* * *}$ & 0.07051 & 0.0760 \\
\hline Age & -0.0124 & -0.0097 & -0.1319 & -0.1342 \\
\hline Study & -0.0034 & 0.00071 & -0.07761 & -0.0802 \\
\hline Income & 0.0044 & 0.01106 & 0.1028 & 0.1065 \\
\hline \multicolumn{5}{|l|}{ Interactive effect } \\
\hline Subjective Norm ${ }^{x}$ Gender & & -0.07862 & & 0.0179 \\
\hline Perceived Behavioral Control ${ }^{\mathrm{x}}$ Gender & & $0.15158^{* * *}$ & & 0.0025 \\
\hline Adjusted R Square & 0.6573 & 0.6731 & 0.6318 & 0.6327 \\
\hline $\mathrm{F}$ & $64.94^{* * *}$ & $48.19^{\star * *}$ & $24.02^{\star * \star}$ & $16.37^{\star * *}$ \\
\hline
\end{tabular}

\section{Discussion}

The results indicate that the Ajzen model fits perfectly to explain IE in Chile (H1a) as in Mei, et al. (2016). However, this model fails to explain in full the EI for the case of students in Colombia. Subjective norm is the variable excluded. It is noteworthy that in previous studies, precisely $\mathrm{SN}$ is the variable that has been less tested empirically. Colombia fits this research group as the results shown by Ruizalba et al., 2015, Tsordia and Papadimitriou, 2015 and Garcia-Rodriguez et al., 2015. Garcia-Rodriguez et al. (2015) show that in a context of less economic development, the role of SN (perceived social pressure) to carry out or not a new firm loses its capacity to EI. It is likely that in this type of economy, other indirect relationships favor EI through $\mathrm{SN}$, which still must be tested for the case of Colombia. It is a fact that there are cultural differences. García-Rodríguez et al. (2015) indicate the existence of cultural differences between both countries in the determinants of EI. Spain showed personal attitude as the principal antecedent, whereas in Senegal, it was PBC.

Results of Rueda Sampedro et al. (2013) are curious for the case of Colombia. Attitude toward entrepreneurship is significantly and SN not directly; however, $\mathrm{SN}$ shows an indirect effect through ATE to EI. To the extent that students perceive a favorable attitude towards their immediate surroundings entrepreneurship, this will influence EI through ATE. That is, ATE would be a mediator between SN and EI.

Another important point of the result is the verification of direct and indirect effect (mediator) of PBC to EI through SLE. Social recognition of entrepreneurship succeeds in linking the capabilities they perceive to have people to create their own business and thereby foster entrepreneurial intention. This finding is very stimulating for public policy for the educational and communicational level. First, the capabilities that people have can be enhanced through a scholarly system that strengths entrepreneurial initiative throughout society. Second, the communicational level is also relevant, the culture could be more pro-entrepreneurship if media give a decisive diffusion about cases of enterprise and availability of resources. The environment could be well perceived working together with government policies and programs that promote an entrepreneurial culture.

The proposed mediating effect followed the approach of Hofstede. It indicates that economies with lower individualism should have more 
enterprising culture. In turn, we expected that social recognition is more forceful in economies with a profile more biased towards a pioneering culture, which, we hoped that the mediating effect both between ATE and PBC to EI is more powerful in Colombia than in Chile. The results show that SLE is a usual mediator role for both countries but only for one variable, ATE (H2a). However, according to the coefficient, the most individualistic country, Chile, would achieve a greater mediating effect. This result is consistent with the proposal of McGrath et al. (1992), who notes that the most enterprising cultures tend to be characterized by a more individualistic profile, unlike indicated by Hofstede. He considers the entrepreneurial activity related to collectivism. This can be understood by the possibility of requiring more collaboration and support networks.

The results partially match Liñán et al. (2011), Khoung and Ann (2016) and Abina et al., (2015) They found that the worth of the venture seems to exert a stronger influence over ATE in the most developed area (Catalonia). Social valuation of entrepreneurship also affects $\mathrm{PBC}$ in a restrictive way for the less developed region (Andalusia). The results of Khoung and Ann (2016), who analyzed 401 students in Vietnam, indicate that external environment (proxy of SLE) and perceived feasibility (PBC) were independent variables and they have a positive and significant impact toward EI. So, foreign climate has an indirect positive effect on EI. Abina et al. (2015) found that selfefficacy (PBC), environmental concern (SLE) and perceived support and perceived barrier have a significant effect on EI.

Finally, it is surprising that gender does not affect all model variables. The results only show that there is no difference in the results of gender as moderator over PBC for both countries. Notably, Colombia has the highest coefficient, which verifies that the economy in which raw biased culture to the stereotype of a man, (the highest rate of MAS according to Hofstede), has a greater impact moderator gender. This variable is nearly related to the capabilities perceived to have a person to orient himself by starting a business. In this case, it is men who have more level of EI related to PBC, as shown in the figure below. Also, as can be seen from the graph, the highest level of recognition of social entrepreneurship more power magnitude effect on the propensity to act on EI. In the research of Zhang et al., (2014) males and population from technological universities and backgrounds have higher EI than females and people from other institutions and backgrounds. There are also significant positive interactive effects by gender, academic type, and study major on the relationship between entrepreneurship education and EI.

We could compare our results with other related. Mueller and Conway (2013) found that among American business students the view of "entrepreneur as male" is fading. This stereotype persists in Spain. Karimi et al. (2013), using TBP explored the effects of gender and role models on EI. No gender differences in the relationship between PBC and EI. Gender affected ATE weaker in females and SN stronger predictor of EI in female students. The results of Sánchez-Escobedo et al. (2014) show the existence of gender differences in EI. More develop country indicates less explanatory power also more conclusive in men than women. Díaz-García and Jiménez-Moreno (2010), both, men and female with a firm EI perceive successful entrepreneurs to have feminine attributes. This result may explain the lack of gender difference in EI. Noguera et al. (2013) indicated that the main findings highlight that "fear of failure" and perceived capabilities are the most important socio-cultural factors on the probability of becoming a woman entrepreneur. Maes et al. (2014) point out diverse factors that predict gender differences in EI. Female are also more motivated to comply with normative role models; this did not influence their EI over PBC and ATE. The moderating effect of gender has a positive impact for women in the relationship between those SN and PBC (Ruizalba et al., 2015).

Results indicate the importance and sensitivity and ATE with SLE and gender PBC with the two Latin American economies. They show that culture, related to social recognition of entrepreneurship, works as a mediator between perceived desirability or attitude toward entrepreneurship and EI. This finding is consistent considering that this is a factor related to the environment, which promotes and enhances the desire to start a new business. In this case, given the low levels of individualism of both economies, this cultural factor does not affect the direct and indirect effects of ATE on EI. The results are very similar for the two countries, the greater light impact for Chile. On the other hand, gender is seen as moderator for the pair variable person, i.e. that referred to the individual perceives that has the capabilities and enough to start a new business control. In this plays an important role masculine characteristics of competitiveness, independence, and aggressiveness.

\section{Conclusion}

Based on information collected for students of business management from two Latin American universities, the study shows that the Ajzen's model best explains EI in the case of Chile and partially for Colombia. Subjective norm does not result significantly for the sample analyzed. The effects of moderation are similar for both countries. The social legitimacy of entrepreneurship mediated attitude toward entrepreneurship. So ATE shows direct and indirect effects through EI. On the other hand, greater SLE does not affect the impact of perceived feasibility or $\mathrm{PBC}$ of EI. The last result is that the moderate effect only is appreciated for Chile, the less male stereotype culture. Gender moderates PBC variable, and men have higher EI.

Besides the stimulating results discussed above, there have to recognize some limitations of the research. The size and type of sample may have been a constraint in this study. In each country, we include students from a single university in each city. However, given the limited number of studies on EI in Latin American countries, our investigation may open news lines of future studies. For example, next researchers may incorporate different factors as moderators or mediators. Such as role models, age, entrepreneurial education, public policies toward entrepreneurship, thus broadening our perspective on the effect that culture and the entrepreneurial environment may have on EI. This work will help others to look forward to more and different relationships with a wider sample, more institutions, careers, and countries. 


\section{References}

Ajzen, I. (1991) The theory of planned behavior. Organizational Behavior and Human Decision Processes, 50, 179-211.

Amorós, J., E., Kuschel, K. and Pizarro, O. (2014). Women and entrepreneurship in Chile 2013/2014. Desarrollo University Press. Santiago, Chile.

Barnir, A.; Watson, W. and Hutchins, H. (2011). Mediation and moderated mediation in the relationship among role models, self-efficacy, entrepreneurial career intention and gender. Journal of Applied Social Psychology, 41(2): 270-297

Busenitz, L., and Lau, C. (1996). A cross-cultural cognitive model of new venture creation. Entrepreneurship Theory and Practice, 20(4), 25-39

Davidsson, P. (1995), "Culture, Structure and Regional Levels of Entrepreneurship", Entrepreneurship \& Regional Development, Vol. 7, Issue 1, Routledge, pp. 41-62.

De Vita, L., Mari., M. and Poggesi., S. (2014). Women entrepreneurs in and from developing countries: Evidences from the literature. European Management Journal. 32(3). pp. 451-460.

Díaz, J.C., and Jiménez. J., (2010) Evaluación del impacto del programa educativo "emprendedores" en la intención emprendedora de los participantes. Universities and Knowledge Society Journal, 12(3), 17-31

Gupta, V. K., Turban, D. B., and Bhawe, N. M. (2008). The effect of gender stereotype activation on entrepreneurial intentions. Journal of Applied Psychology, Vol. 93, pp.1053-1061.

Guzmán-Alfonso, C. and Guzmán-Cuevas, J. (2012). EIs models as applied to Latin America. Journal of Organizational Change Management, 25(5), 721-735.

Hofstede, G. (1980) “Culture’s Consequences: International Differences in Work-Related Values” Beverly Hills CA: Sage Publications.

Kibler, E., Kautonen, T and Finks, M. (2014). Regional Social Legitimacy or Entrepreneurship Implications for EI and Start-up Behavior, Regional Studies 48(6), 995-1015.

Krauss., S., Frese. M., Friederich C., and Unger. J. (2005) Entrepreneurial orientation: A psychological model of success among southern African small business owners. European Journal of Work and Organizational Psychology 14 (3): 315-44

Krueger, N. F. and Brazeal, D. V. (1994). Entrepreneurial Potential and Potential Entrepreneurs. Entrepreneurship Theory and Practice, 18(3), 91-104.

Krueger, N. F., Jr. Reilly, M. D. and Carsrud, A. L. (2000). Competing Models of EIs. Journal of Business Venturing, 15, 411-432.

Liñán, F., Santos, F., and Fernández, J. (2011). The influence of perceptions on potencial entrepreneurs. International Entrepreneurship Management, 7, 373-390.
Liñán, F. and Chen,Y. (2009). Development and cross-cultural application of a specific instrument to measure EIs. Entrepreneurship Theory and Practice, 33(3), 593-617.

Maes, J.; Leroy, H.; and Sels, L. (2014). Gender differences in entrepreneurial intentions: A TPB multi-group analysis at factor and indicator level. In press.

Moriano. J., Gorgievski. M., Laguna. M., Stephan. U. and Zarafshani. K. (2012). 'A cross-cultural approach to understanding entrepreneurial intention. Journal of Career Development', Vol. 39, No. 2, pp. 162-185.

Mueller, S. and Conway, M. (2013). A cross cultural study of genderrole orientation and entrepreneurial self-efficacy. En: International Entrepreneurship and Management Journal, 9: 1-20

North, D. (2005). Understanding the Process of Economic Change, Princeton, University Press.

Ruizalba. J., Vallespin. M. Martin-Sanchez. V., and Rodriguez-Molina. $M$ (2015). The moderating role of gender on entrepreneurial intentions: A TPB perspective. Intangible Capital. Vol. 11. No 1. Pp 92 -117.

Sánchez. J. (2009). Aprendizaje social e intenciones emprendedoras: un estudio comparativo entre México, España y Portugal. Revista Lationamericana de Psicología. 41(1),109-119.

Shane, S. A. (2000). "A general theory of entrepreneurship: The individual-opportunity nexus”. Edward Elgar Publishing.

Shapero, A., and Sokol, L., (1982). The Social Dimensions of Entrepreneurship, in C. Kent, D. Sexton, and K. H. Vesper (eds.) The Encyclopedia of Entrepreneurship. Englewood Cliffs, NJ: Prentice-Hall. 72-90.

Strobl, A., Christopher, K., and Mike, P. (2012). Entrepreneurial attitudes and intentions: assessing gender specific differences. International Journal of Entrepreneurship and Small Business, 15(4), 452-468.

Suchmann, M. (1995) Managing Legitimacy: strategic and institutional approaches, Academy of Management Review, 20, 571-611.

Thompson, E.R. (2009) Individual Entrepreneurial intent: Construct clarificatioan and development of an internationationally reliable metric. Entrepreneurship Theory and Practice, 33 (3),669-694.

Veciana, J.M. (2005). La Creación de Empresas: un enfoque gerencial, Colección de estudios económicos, La Caixa, Barcelona

Ventura, R. and Quero, M. (2013). Factores explicativos de la intención de emprender en la mujer. Aspectos diferenciales en la población universitaria según la variable género. Cuadernos de Gestión, 13(1): 127-149.

Verheul, I., Thurik, R., Grilo, I., and Zwan, P. (2012). Explaining preferences and actual involvement in selfemployment: gender and the entrepreneurial personality. Journal of Economic Psychology, 33(2), $325-341$ 